\title{
Study of flow regimes and gas holdup in a different potentials medium in an aerated column
}

\author{
Konstantin Prokhorov ${ }^{1 *}$, Alexander Burdonov ${ }^{2}$ and Peter Henning ${ }^{3}$ \\ ${ }^{1}$ Mining Institute FEB RAS, 51 Turgenev st., Khabarovsk, 680000, Russia; \\ ${ }^{2}$ FSBEI HE Irkutsk National Research Technical University, 664074, Irkutsk, Russia; \\ ${ }^{3}$ SIEMAG TECBERG group, Haiger, Germany
}

\begin{abstract}
Annotation. A generation of hydrogen and oxygen bubbles by of aqueous solutions of electrolytes was carried out. Two electrolysis modifications was study: electrolysis without a membrane to production of oxygen and hydrogen and membrane electrolysis with separation of catholyte and anolyte. The influence of the model conditions of the experiment such as electrolyte $\mathrm{pH}$, concentration, and current density and the distribution of bubble sizes and gas holdup in the column are discussed. An inverse dependence of the hydrogen bubbles diameter in the catholyte medium on the current density and a direct dependence on the concentration of electrolytes are experimentally investigated. The oxygen bubbles tend to become larger with increasing current density and electrolyte concentration in anolyte medium. In electrolysis without a membrane, bubbles become smaller with increasing current density and decreasing the electrolyte concentration.
\end{abstract}

\section{Introduction}

Flotation processes are very effective for separating fine particles in mineral processing. The efficiency of flotation processes depends on effective collision between micro-bubbles and particles, which is influenced by their size and potential $[1,2]$.

Diameter and distribution of the bubbles generated by water electrolysis are important in the electroflotation process of fine particles. It is well known that these parameters influence the efficiency of the flotation process because they affect the collision, adhesion, and transport mechanisms. Moreover, the smaller the bubble diameter, the better the recovery of fines due to the larger surface area of the bubble. The study are shows that efficiency is highest when bubbles and particles have opposite surface charges and are of similar sizes.

In our practice, electroflotation is used in the processes of extracting metal cations during the waste water purification from mining plants and chemical industries [3-5]. A review of the foreign works also shows of the electroflotation of cationic forms of metals $[6,7]$.

However, the potential of the electroflotation process can be expanded by using it in the mining process of fine minerals. As a variation of the flotation process, electroflotation is extremely versatile and competitive in relation to air flotation. The bubble sizes of

*Corresponding author: Kostyan1986_ne@mail.ru 
electroflotation process are smaller in comparison with air flotation, wherein the bubbles charge and the medium in flotation column can be controlled [8].

The characteristics of the electrode, such as shape, diameter, and electrode surface, $\mathrm{pH}$ of medium, the current density and electrolyte concentration influence gas formation and distribution and the diameter of the bubble [9-11].

Multiple studies have been carried out aiming to understand the influence of different factors on the bubble size generated by water electrolysis. It is important to note that most of these investigations have addressed the effect of different factors on bubble size of a hydrogen and oxygen mixture. In this work, a comparative characteristic of the gas holdup and the size of the formed hydrogen and oxygen bubbles will be carried out during electrolysis in a one chamber column and separate electrolysis in a specially designed a two chamber column.

The purpose of this study is to analyze the effect of simulated electrolysis conditions on the process of gas holdup, the bubbles formation and size in the column.

Different electrolytes with own $\mathrm{pH}$, various concentration of electrolytes and the current density, and a separate medium for the bubbles will be experimentally study.

\section{Materials and methods}

\subsection{Electrodes}

Stainless steel mesh were used as both cathode and anode. Diametr of wire is $0.25 \mathrm{~mm}$. A form of electrodes is rectangle in non-membrane electrolyze and it is round form following the shape of the column bottom in membrane electrolyze. Electrodes area are same in both case.

\subsection{Bubble generation by electrolysis}

Electrolysis was carried out by two versions

1. Non-membrane electrolysis was performed on column of $850 \mathrm{ml}$ volume and $300 \mathrm{~mm}$ hight (fig. 1). Both anode and cathode was setup in middle of column bottom. The gap between electrodes was $5 \mathrm{~mm}$.

2. Membrane electrolysis was performed on column is shown on fig. 2 . The catholite with hydrogen bubbles or anolite with oxygen bubbles are produced in a main cells of two-cells column. The main cell of column is $850 \mathrm{ml}$ volume and $300 \mathrm{~mm}$ hight. Cells was separated by membrane. Anode and cathode were installed on both sides of membrane.
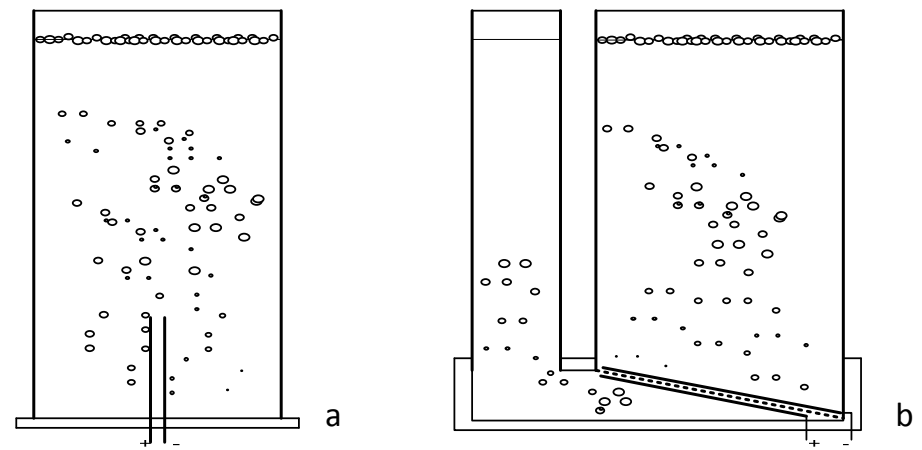

Fig. 1. Electroflotation column

a) Non-membrane column, b) membrane column. 


\subsection{Main parameters of electrolysis}

\subsubsection{Gas hold up}

During experiments the gas hold ups were determined by the bed height method as shown in [12] and were calculated by Eq. 1:

$$
\mathrm{E}=\left(\mathrm{H}_{\mathrm{T}}-\mathrm{H}_{0}\right) * 100 \% / \mathrm{H}_{\mathrm{T}}
$$

Where: $\mathrm{H}_{\mathrm{T}}$ is total height of gas-liquid emulsion; $\mathrm{H}_{0}$ is static height of liquid.

\subsubsection{Bubble sizes}

In order to determine the bubble size distributions at specific cell level and the bubbles diameter, images of bubble flow were taken by digital video camera. A wire of known diameter $(0.16 \mathrm{~mm})$ was taped for use as the calibration factor for the bubble size. For getting a sufficiently. Every time more than 200 bubbles were determined for getting a sufficiently representative bubble size distribution.

The size of each generating bubbles directly depends on the many factors. Its will different in same production conditions. Thus, we investigated the average bubbles diameters. The average diameter is calculated by Eq. 2 .

$$
\operatorname{Dcp}=\left(\sum\left(\mathrm{n}_{\mathrm{i}} \mathrm{d}_{\mathrm{i}}\right)\right) / \mathrm{N}_{\mathrm{b}}
$$

where: $\mathrm{n}_{\mathrm{i}}-$ number of bubble with $\mathrm{d}_{\mathrm{i}}$ diameter; $\mathrm{N}_{\mathrm{b}}-$ total number of bubbles.

Experiments were conducted with different model aqueous solution $(0,05$ and $0,1 \mathrm{~mol} / \mathrm{l})$ $\mathrm{NaHCO}_{3}$ and $\mathrm{NaOH}$ by volume at current density from 6 to $62 \mathrm{~mA} / \mathrm{cm}^{2}$

The flow of the gas bubbles formed during electrolysis was generated due to the following reactions that occur at the electrodes:

$$
\begin{aligned}
& \text { anode: } 2 \mathrm{H}_{2} \mathrm{O}=\mathrm{O}_{2}(\mathrm{~g})+4 \mathrm{H}^{+}+4 \mathrm{e}^{-} \\
& \text {cathode: } 2 \mathrm{H}_{2} \mathrm{O}+2 \mathrm{e}^{-}=\mathrm{H}_{2}(\mathrm{~g})+2 \mathrm{OH}^{-}
\end{aligned}
$$

\section{Results and discussion}

\subsection{Depend of gas hold ups on medium modeling parameters and current density in non-membrane electrolysis}

The variations of gas hold ups at different current density with different model solutions are shown in Fig. 2.

As shown in Fig. 2, increasing of current density increases the gas hold ups but it depends on the electrolyte concentration (density, viscosity) (Table 1).

Increasing the electrolyte concentration has a small negative effect on the gas hold ups when we use $\mathrm{NaHCO}_{3}$ with $\mathrm{pH}$ 8.4. When is used $\mathrm{NaOH}$ with $\mathrm{pH} 12$, the gas hold ups not depending on electrolyte concentration.

Table 1. Dependence the electrolyte density on concentration.

\begin{tabular}{|c|c|c|c|c|}
\hline \multirow{2}{*}{ Electrolyte } & \multirow{2}{*}{$\mathrm{pH}$} & \multicolumn{3}{|c|}{ Concentration } \\
\cline { 3 - 5 } & & 0.05 & 0.1 & 0.15 \\
\hline $\mathrm{NaHCO}_{3}$ & 8.4 & 1.0012 & 1.0043 & 1.0073 \\
\hline $\mathrm{NaOH}$ & 12 & 1.0005 & 1.0027 & 1.0049 \\
\hline
\end{tabular}

This can be attributed to the proton activity of the electrolyte. It directly depends on the $\mathrm{pH}$ of the medium. The negative effect of the solution density can be compensated for by the hydration activity and mobility of anions in $\mathrm{NaOH}$ medium. According to [13], the mobility of the $\mathrm{OH}^{-}$anion is almost 5 times higher than the $\mathrm{HCO}^{-}$anion. It can explain why gas hold ups in non-membrane electrolysis does not depend on the $\mathrm{NaOH}$ concentration. 


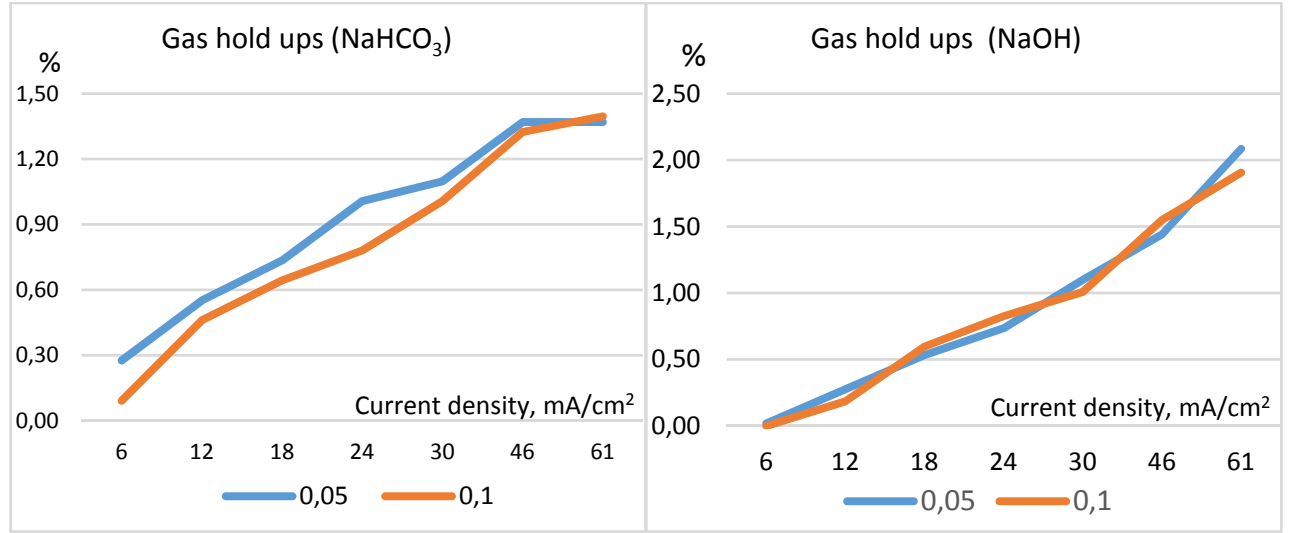

Fig. 2. Gas hold ups in non-membrane electrolysis

\subsection{Depend of gas hold ups on medium modeling parameters and current density in membrane electrolysis.}

The variations of gas hold ups at different current density in catholite medium with different model solutions are shown in Fig. 3.

For producing catholite with hydrogen bubbles only was used semipermeable membrane.

Since cation $\mathrm{Na}^{+}$carry of charge in both investigated medium, in this case ions activity does not compensate much the medium density negative influence. The best result of gas hold ups was received on $0.05 \mathrm{~mol} / \mathrm{l}$ electrolyte.

But ions activity is important. The current density didn't rise above $31 \mathrm{~mA} / \mathrm{cm}^{2}$ in the $0.05 \mathrm{~mol} / 1 \mathrm{NaHCO}_{3}$ medium, because of low $\mathrm{HCO}_{3}{ }^{-}$ions activity.

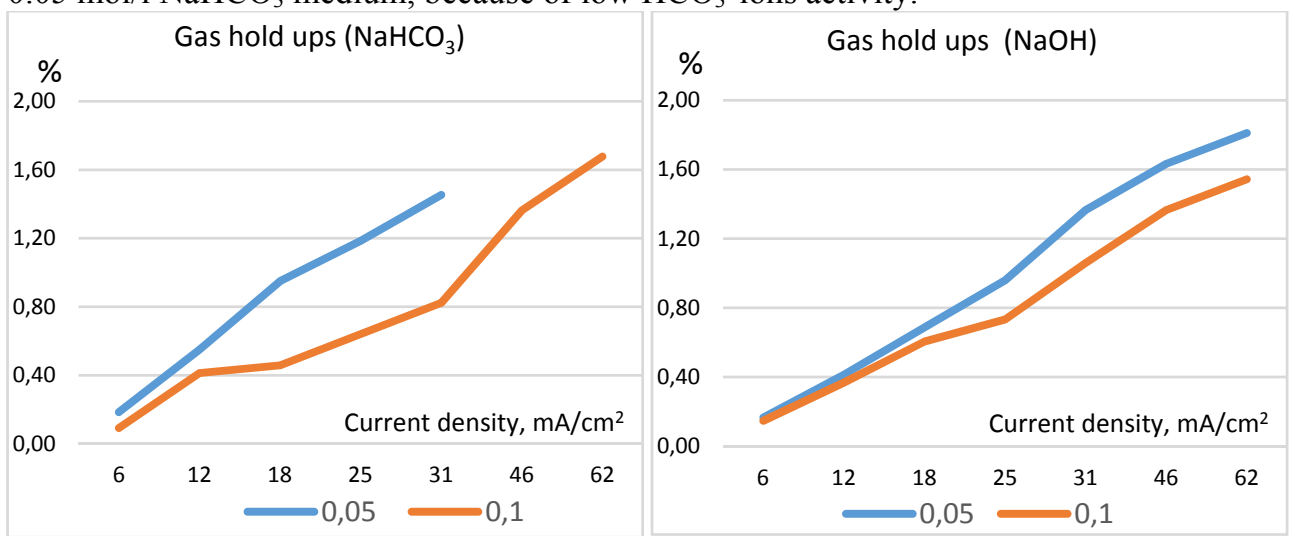

Fig. 3. Gas hold ups of hydrogen bubbles in membrane electrolysis

\subsection{Influence of concentration electrolyte and current density on the average bubble size}

\subsubsection{Non-membrane electrolysis}

The effect of concentration on the average bubble diameter for different current densities are shown in fig. 4.

The average bubble diameter increases with decreasing electrolyte concentration. This situation is opposite to the dependence of the distribution of bubble sizes on concentration in 
membrane electrolysis. What will be shown below. It can be assumed that this effect occurs due to the coalescence of detachment oxygen and hydrogen bubbles. The solution has a lower density and viscosity at a lower electrolyte concentration. The flow of bubbles is faster in less density medium, and the bubbles detach from the electrodes with a greater speed. Bubbles have a high probability of hitting and coalescing due to the small gap of the electrodes. The generated microbubbles hydrogen and oxygen are surrounded by opposite charges, resembling a double electric layer. The opposite charges bubbles coalesce to a greater extent on collision, in contrast to similarly charged ones.

The second hypothesis of this behavior is increasing the protons activity in increasing electrolyte concentration. Some of the detachment hydrogen bubbles are removed from the electrode faster due to this activity. It reducing the chance of coalescence.

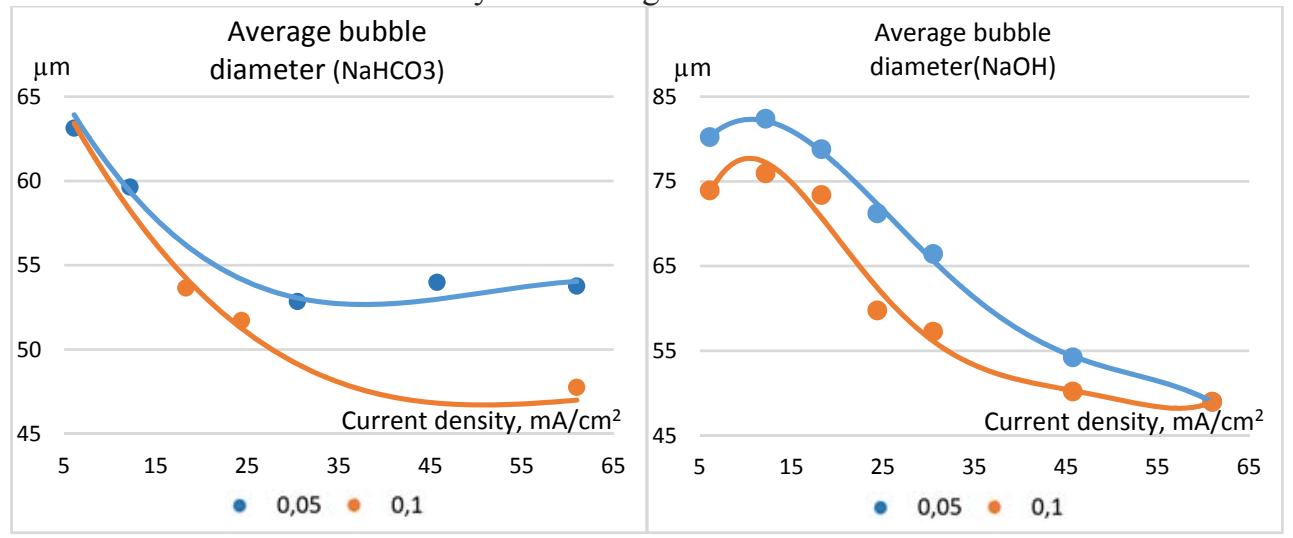

Fig. 4. Average bubble diameter in non-membrane electrolysis

\subsubsection{Membrane electrolysis.}

Dependence of the average hydrogen bubble diameter on concentration for different current densities are shown in fig. 5.

In comparison with non-membrane electrolysis, increasing of electrolyte concentration increases the average hydrogen bubble diameter. This dependency less at current density from 16 to $25 \mathrm{~mA} / \mathrm{cm}^{2}$. Increasing of electrolyte concentration increases density and vescocity of solution. This directly affects the hold process of the increasing bubbles on electrode.

Average hydrogen babbles size increases at current density till $12 \mathrm{~mA} / \mathrm{cm}^{2}$, but general trend is decrease by increasing current density.

Fig. 6 shows dependence of the average oxygen bubble diameter on concentration for different current densities.

The average oxygen bubble size plot shows oxygen bubbles increase with increasing current density and electrolyte concentration. However, when $\mathrm{NaHCO}_{3}$ is used, a noticeable dependence of the oxygen bubbles size on concentration is observed to a $25 \mathrm{~mA} / \mathrm{cm}^{2}$ current density. With a further increase in the current density, the electrolyte concentration does not affect the size. When $\mathrm{NaOH}$ is used the oxygen bubbles size increases with increasing concentration, over the entire range of current density. This picture confirms the contribution of the proton and hydration activity of the electrolyte to the bubble generation process. The average oxygen bubbles size increase does not greatly affect the total gas hold ups. The small hydrogen bubbles maintain an increase in gas hold ups during electrolysis without a membrane. 


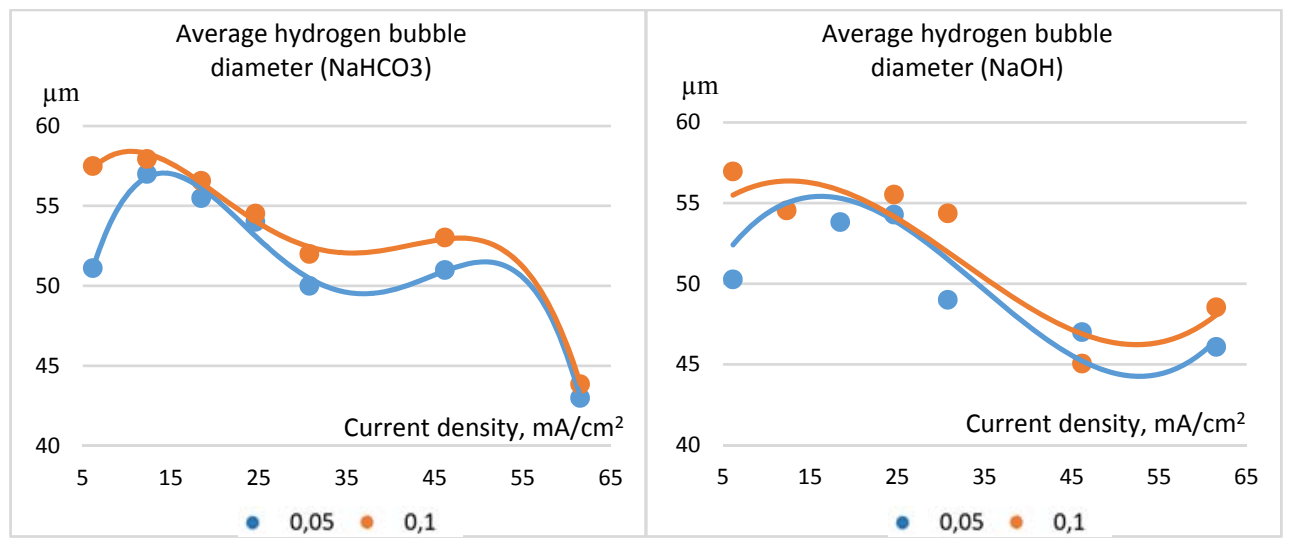

Fig. 5. Average hydrogen bubble diameter in catolite in membrane electrolysis.
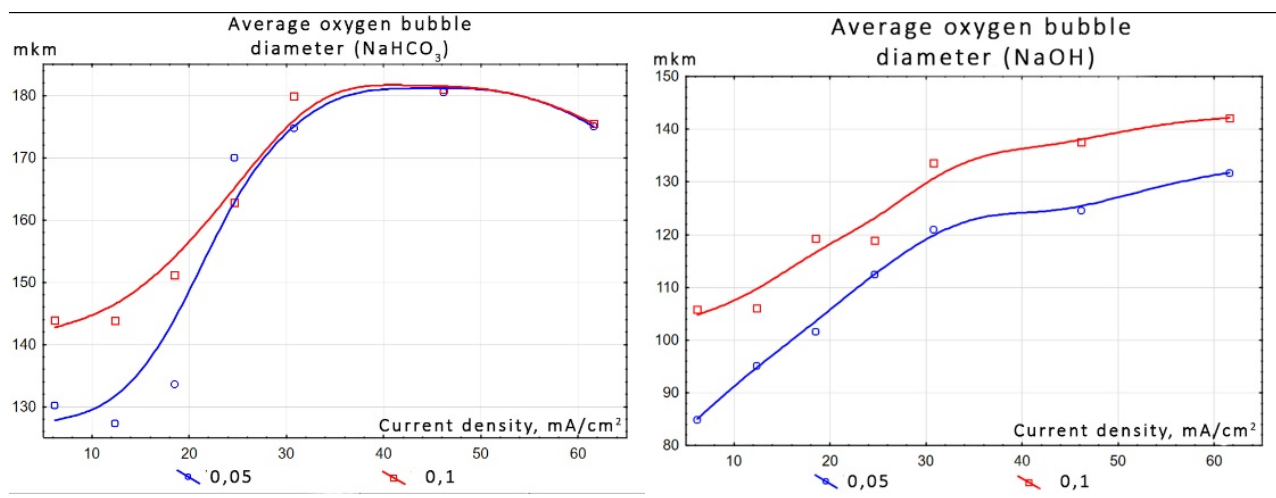

Fig. 6. Average oxygen bubble diameter in anolite in membrane electrolysis.

\subsection{Influence of concentration electrolyte and current density on the bubble size distribution.}

The number-based cumulative size distributions of the bubbles for each experiment were calculated and plotted. Fig. 7 and 8 shown the distribution for $\mathrm{NaOH}$. All data obtained show a rather wide range of bubble sizes in both membrane electrolysis and non-membrane one. The range of bubble sizes depend only on current density. No consistent trends in the distributions are observed with electrolyte concentration (density).

The bubble size distributions data show that the wide range of bubble sizes produced at different current densities. The main range of bubble sizes is $20-100$ up to $31 \mu \mathrm{A} / \mathrm{cm}^{2}$. In current density over $31 \mu \mathrm{A} / \mathrm{cm}^{2}$ main range of bubble sizes became 20-50 $\mu \mathrm{m}$. The same trend of size distribution was observed with 0.05 and $0.1 \mathrm{~mol} / 1 \mathrm{NaHCO}_{3}$ model solutions studied. 


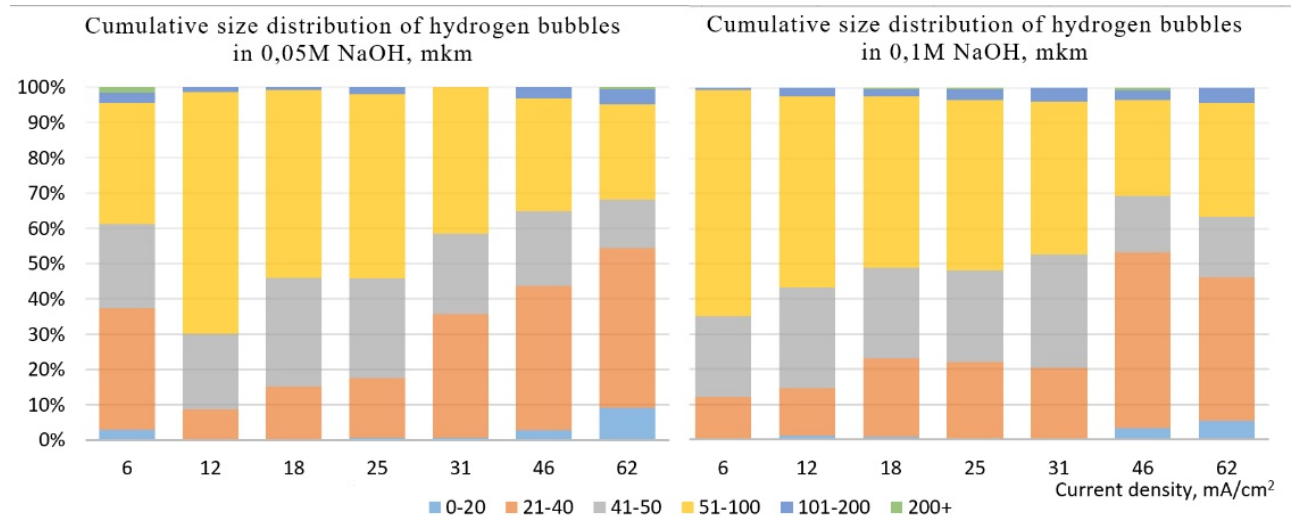

Fig. 7. Distribution of hydrogen bubbles size in catolite in membrane electrolysis.

Cumulative size distribution of bubbles in $0,05 \mathrm{M} \mathrm{NaOH}, \mathrm{mkm}$

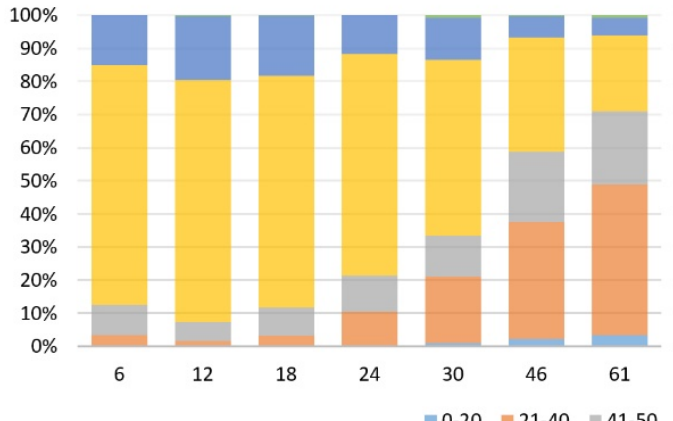

Cumulative size distribution of bubbles in $0,1 \mathrm{M} \mathrm{NaOH}, \mathrm{mkm}$

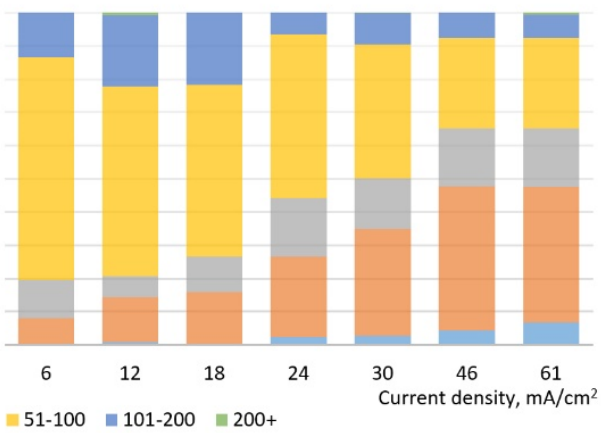

Fig. 8. Distribution of bubbles size in non-membrane electrolysis.

\section{Conclusion}

From the experimental studies the following conclusions can be drawn:

1. The gas hold ups tend to increase with current density and decrease with the increase of electrolyte concentration (it is effect of the density and viscosity of the solution). The gas hold ups increasing become significant only at $18 \mu \mathrm{A} / \mathrm{cm}^{2}$ current density.

2. The average hydrogen bubbles diameter is inversely dependent on current density and directly dependent on electrolyte concentration in membrane electrolysis. The diameter of hydrogen bubbles generally decreases, although it has some growth in the range of 6-12 $\mu \mathrm{A} / \mathrm{cm}^{2}$. The diameter of oxygen bubbles increases with increasing current density and electrolyte concentration.

3. The contribution of oxygen bubbles does not exceed the contribution of hydrogen bubbles in non-membrane electrolysis, and the average bubble diameter of the gas phase decreases. However, bubble size is inversely dependence to electrolyte concentration. This is explained by the activity of protons and it influence on the coalescence of the separating bubbles.

4. Wide range of bubble sizes depend only on current density. No consistent trends in the distributions are observed with electrolyte concentration (density). Increasing the current density decreases of bubble sizes. 
Research was supported by Scientific grant "Increasing the complexity of the use of mineral raw materials of various genesis on the basis of its systemic mineralogical and technological assessment and a differentiated approach to determining the content of precious metals by their modes of occurrence" is provided by the Government of Khabarovsk Territory (59C/2020, 21.08.2020).

Experimental research was carried out on the basis of the Center for Collective Use of the Khabarovsk Federal Research Center FEB RAS.

\section{References}

1. M.Y. Han, AQUA, 51(1), 27-34 (2001)

2. M.Y. Han, W.T. Kim and S. Dockko, Water Sci. Technol., 43(8), 139-144 (2001)

3. V. A. Chanturiya, I. V. Shadrunova, N. L. Medyanik, O. A. Mishurina, FTPRPI (Journal of Mining Science), 3, 89-97 (2010)

4. V. A. Brodskij, V. I. Il'in, V. A. Kolesnikov, Teoreticheskie osnovy himicheskoj tekhnologii, 2(49), 144-150 (2015)

5. E.N. Alekhina, E.R. Barieva, Sovremennye innovacii, 3(31), 11-12 (2018)

6. Rasha H. Salman. Iraqi Journal of Chemical and Petroleum Engineering, 20, 39-48 (2019)

7. G.Z. Kyzas, N.K. Lazaridis, K.A. Matis, Interface Science and Technology, 30, 15$42(2019)$

8. M.Y. Han, M.K. Kim, H.J. Ahn, Water Science \& Technology, 53(7), 127-132 (2006)

9. V.G. Nefedov, A.G. Atapin, Voprosy himii i himicheskoj tekhnologii, 4, 120-126 (2019)

10. Md. Shahjahan Kaisar Alam Sarkar, G.M. Evans, S.W. Donne, Minerals Engineering, 23, 1058-1065 (2010)

11. L Ben Mansour, S Chalbi, I Kesentini, Indian Journal of Chemical Technology, 14, 253-257 (2007)

12. A. Prakash, A. Margaritis, H. Li, M.A. Bergougnou, Biochemical Engineering Journal, 9, 155-163 (2001)

13. N.A. Svarovskaya, I.M. Kolesnikov, V.A. Vinokurov. Elektrohimiya rastvorov elektrolitov. CHast' I. Elektroprovodnost': Uchebnoe posobie. Izdatel'skij centr RGU nefti i gaza (NIU) imeni I.M. Gubkina (2017) 